\title{
Granuloma letal da linha média: abordagem clínica e terapêutica de três casos
}

\author{
D. M.M. Borducchi, G. W. B. Colleoni, J. S. R. de Oliveira, A. C. Alves, O. Cervantes, R. A. Segreto, \\ J. KERBAUY
}

Departamento de Anatomia Patológica e Disciplinas de Hematologia e Hemoterapia; Cirurgia de Cabeça e Pescoço e de Radioterapia da Universidade Federal de São Paulo - Escola Paulista de Medicina, São Paulo, SP.

\begin{abstract}
Resumo - Овj etivo. Relato de três casos do GLLM acompanhados pela Disciplina de Hematologia e Hemoterapia da Unifesp-EPM que tiveram boa resposta à terapêutica e evolução favorável.

Métodos. Após confirmação histológica e histoquímica, os pacientes foram submetidos à tratamento quimio e radioterápico com boa resposta terapêutica.
\end{abstract}

Resultados. Atualmente estes pacientes encontram-se em remissão total da doença, com

\section{INTRODUÇÃO}

O granuloma letal da linha média (GLLM) corresponde a um grupo de doenças raras, caracterizadas por processo destrutivo de partes moles envolvendo estruturas do trato respiratório superior (nariz, seios paranasais, palato e tecidos moles faciais). Alguns casos com envolvimento pulmonar e de SNC representam uma entidade diferente ${ }^{1}$. O curso clínico desta doença parece depender da proporção de células grandes observadas no exame anatomopatológico, podendo assumir forma indol ente ou agressiva ${ }^{1}$.

O quadro citológi co característico é de invasão da parede vascular e, usualmente, oclusão do lúmen por células linfóides com variados graus de atipia. Na maioria dos casos as células atípicas expressam antígenos pan -T (CD2+, CD5+/-, CD $7+/-)$, mas são freqüentemente CD3 -, podendo ser CD4+ ou CD8+ e CD56 $t^{2,3}$.

Atualmente o GLLM é considerado um linfoma de origem $T$ e foi recentemente incluído na classificação R.E.A.L. (Revised E uropean-American Classification) pelo International Lymphoma Study Group sob a denomi nação de linfoma angiocêntrico ${ }^{4}$. Apesar da evolução clínica de pacientes com GLLM na maioria dos casos ser bastante desfavorável ${ }^{5}$, relatamos três casos de GLLM acompanhados pela Disciplina de Hematologia e Hemoterapia da Unifesp-EPM que tiveram boa resposta à terapêutica e evolução favorável. sobrevida média de $\mathbf{4 5}$ meses.

Conclusão. Levando-se em consideração nossa pequena experiência, acreditamos que o tratamento radioterápico e a abordagem quimioterápica inicial agressiva são fundamentais para uma boa evolução deste ti po de linfoma.

UNITERMOS: Linfoma não-Hodgkin. Linfoma angiocêntrico. Tratamento.

\section{RELATO DE CASO}

Relatamos três casos de GLLM, diagnosticados entre março/1995 e fevereiro/1997 no ambulatório de LNH da Unifesp-EPM. Um paciente pertencia ao sexo masculino e dois ao feminino, com idades ao diagnóstico de 28, 35 e 58 anos, respectivamente. Todos foram considerados como estadio I B E (Tabela 1), de acordo com os critérios de Ann Arbor $^{6}$, e classificados como linfoma T devido à positividade ao CD45 Ro e negatividade do CD20, na imuno-histoquímica. A revisão das biópsias dos três casos, de acordo com a classificação R.E.A.L., revelou o diagnóstico de linfoma angiocêntrico (Figuras 1 e 2). Os pacientes foram submetidos à tratamento local com radioterapia (3.600 - 4.000 cGy) e tratamento sistêmico com quimi oterapia, esquema MVPP (4 - 6 ciclos). Esse esquema quimioterápico consiste de mostarda nitrogenada 6 $\mathrm{mg} / \mathrm{m} 2$ IV no primeiro e oitavo dias, vinblastina 6 $\mathrm{mg} / \mathrm{m} 2$ IV no primeiro e oitavo dias, procarbazina $100 \mathrm{mg} / \mathrm{m} 2$ VO por 14 dias e prednisona $60 \mathrm{mg} / \mathrm{m} 2$ por 14 dias. A sobrevida dos pacientes em janeiro/ 1998 era de 32, 24 e 34 meses, respectivamente. Atual mente, todos encontram-se em remissão completa da doença, em acompanhamento ambulatorial periódico.

\section{DISCUSSÃO}

Existem, habitualmente, dois problemas que necessitam ser resolvidos quando se suspeita do 


\begin{tabular}{|c|c|c|c|}
\hline Exames & Caso 1 & Caso 2 & Caso 3 \\
\hline Sexo/ldade & $\mathrm{M} / 28$ anos & $\mathrm{F} / 35$ anos & $\mathrm{F} / 58$ anos \\
\hline Hemograma & $\begin{array}{c}\mathrm{Hb}-10,6 \mathrm{~g} / \mathrm{dl} ; \mathrm{Ht}-31 \% \\
\text { GB- } 7.400 / \mathrm{mm} 3 ; \\
\text { Plaquetas- } 380.000 / \mathrm{mm} 3\end{array}$ & $\begin{array}{c}\mathrm{Hb}-11,3 \mathrm{~g} / \mathrm{dl} ; \mathrm{Ht}-34 \% \\
\text { GB- } 5.100 / \mathrm{mm} 3 ; \\
\text { Plaquetas- } 200.000 / \mathrm{mm} 3\end{array}$ & $\begin{array}{c}\mathrm{Hb}-10,0 \mathrm{~g} / \mathrm{dl} ; \mathrm{Ht}-32 \mathrm{~g} \% \\
\text { GB-5.500/mm3; } \\
\text { Plaquetas- } 318.000 / \mathrm{mm} 3\end{array}$ \\
\hline Creatinina & 1,0 & 0,6 & 1,2 \\
\hline TGO/TGP & 09/07 & $16 / 15$ & $29 / 18$ \\
\hline VHS/DHL & $55 / 128$ & 33/733 & $67 / 226$ \\
\hline Anti-HIV & Negativo & Negativo & Negativo \\
\hline HTLV-I & Negativo & Negativo & Negativo \\
\hline ANCA & Negativo & Negativo & Negativo \\
\hline CT tórax & Sem alterações & Sem alterações & Sem alterações \\
\hline CT abdome & Sem alterações & Sem alterações & Sem alterações \\
\hline Biópsia & Linfoma Angiocêntrico & Linfoma Angiocêntrico & Linfoma Angiocêntrico \\
\hline $\begin{array}{l}\text { Imuno } \\
\text { Histoquímica }\end{array}$ & $\mathrm{T}$ & $\mathrm{T}$ & $\mathrm{T}$ \\
\hline BMO & Normal & Hipocelular & Normal \\
\hline
\end{tabular}

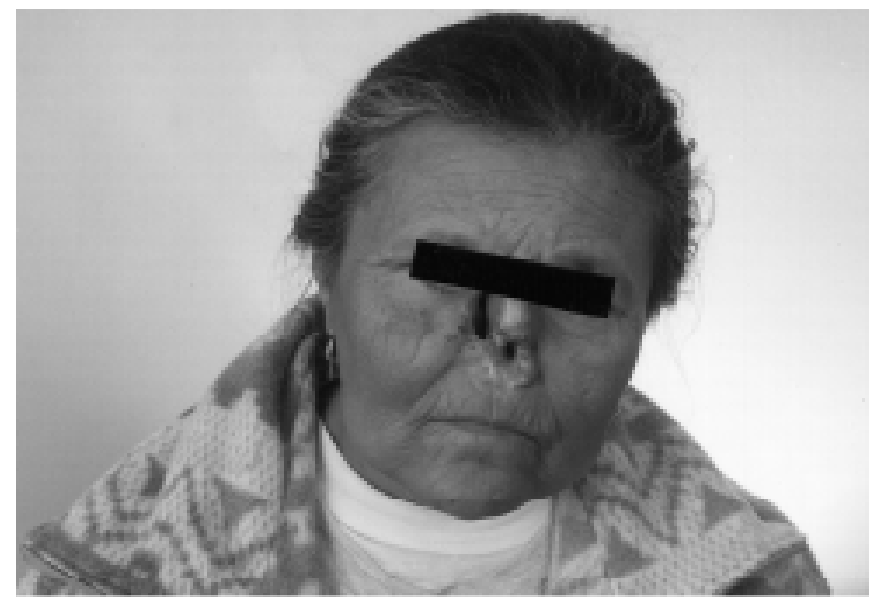

Fig. 1 - Caso 3: paciente apresentando extensa lesão destrutiva, de limites imprecisos, comprometendo pele, tecido cartilaginoso e ósseo da região nasal.

diagnóstico de GLLM. Primeiro, diferenciá-lo clínica, bacteriológica e epidemiologicamente dos outros granulomas, especialmente da granulomatose de Wegener (GW). Segundo, diferenciá-lo dos outros tipos de linfoma, principalmente do linfoma extra-nodal de origem B, de acordo com características imunopatológicas ${ }^{7}$. Mas, em contraste com a GW, a genuína vasculite nunca é observada no GLLM ${ }^{8}$. Outra diferença entre GLLM e GW, é a presença de ANCA (antineutrophil cytoplasm antibodies) na maioria dos casos de $\mathrm{GW}^{9}$, sendo a pesquisa deste anticorpo negativa nos nossos casos.

Entre as numerosas formas de tratamento propostas para GLLM , a radioterapia parece ser a de maior sucesso. Quimioterapia isolada parece ter

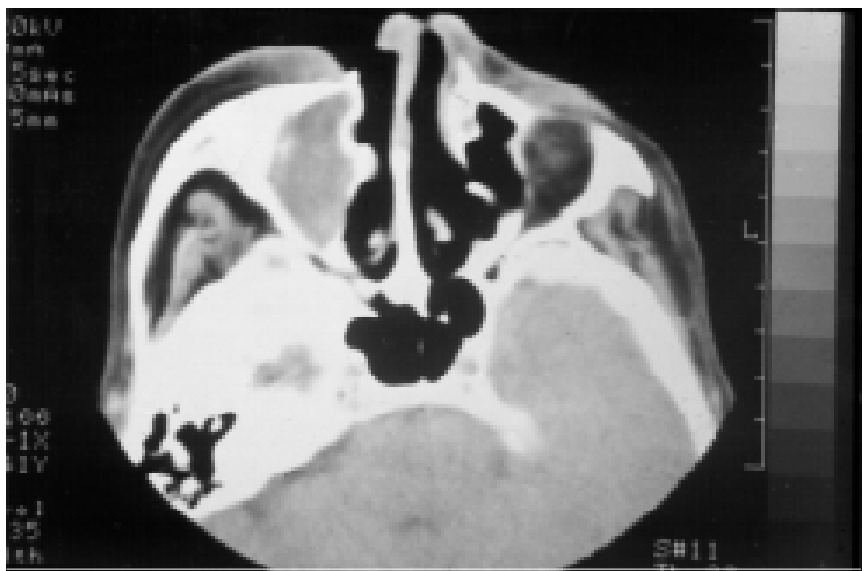

Fig. 2 - Caso 3: Tomografia computadorizada de crânio, com comprometimento de estruturas de partes moles do nariz e destrui ção de tecidos ósseo e cartilaginoso do septo nasal.

um efeito pequeno e quando obtida, a remissão é rara e de curta duração. Finalmente, o interferon al pha- 2 b recombinante tem sido utilizado em alguns casos para manutenção da remissão ${ }^{10}$.

O tempo de evolução do GL L M é variável, entre 3 e 20 meses, e o óbito pode ocorrer por infecção secundária, hemorragia provocada pela erosão de vasos maiores da cabeça e do pescoço e caquexia ${ }^{5}$. Nós acreditamos que quimio e radioterapia combinadas representam a mel hor forma de tratamento para esta doença, com possibilidade de reconstrução estética das lesões nasais e melhora da qualidade de vida dos pacientes que atingem remissão completa contínua. Obtivemos boa resposta com o tratamento quimio e radioterápico associados à 
profilaxia de infecção dos seios paranasais (sulfametoxazol-trimetoprima $400 \mathrm{mg} / \mathrm{dia}$ ) e todos os nossos pacientes encontram-se em remissão completa com sobrevida acima do esperado, sendo que apenas o caso 3 (Figura 1 ) necessitou de cirurgia plástica reparadora. Provavelmente a evolução favorável dos nossos pacientes possa estar associada à forma menos agressiva (indol ente) de manifestação do linfoma angiocêntrico.

Concluímos, a despeito de nossa pequena experiência, que o GL LM não é sempre "letal" sendo a denominação linfoma angiocêntrico mais adequada principalmente para os casos com evolução indolente, e que a abordagem inicial agressiva é fundamental para uma boa evolução.

\section{SUMMARY}

Lethal midline granuloma: clinical management of three cases Most part of L MG (Lethal Midline Granuloma) have a more unfavorable outcome than other kinds of $T$ nonHodgkin's Iymphoma.

Purpose. Wereport three cases of LMG followed at Disciplina de Hematologia e Hemoterapia from Unifesp-EPM with good response to conventional treatment and favorable outcome.

Methods. After histological and histochemical analyses, patientes were treatd with combined chemo-and radiotherapy with favorable evolution.

Results. Currently they present clinical complete remission, with mean survival of 45 months.

ConCLUSION. Despite of our small experience, we bel ieve that combined aggressive therapy is extremely important for further favorable evolution in this type of Iymphoma. [Rev Ass Med Brasil 1999; 45(2): 194-6.]

KEY WORDS: Lethal midline granuloma. Non-Hodgkin lymphoma. Treatment.

\section{REFERÊNCIAS BIBLIOGRÁFICAS}

1- Lipford E, Margolich J , Longo D. Angiocentric immunoproliferative lesions: a clinicopathologic spectrum of post-thymic Tcell proliferations. Blood 1988; 5:1.674.

2- Chan J , Ng C, Lau, W. Most nasal/nasopharyngeal lymphomas areperipheral T cell neoplasms. AmJ SurgPathol 1987; 11: 418.

3- Ferry J , Sklar J , Zukerberg L. Nasal Lymphoma: a clinicopathologic study with immunophenotypic and genotypic analysis. Am J Surg Pathol 1991; 15: 268.

4- Harris, N.L.; J affe, E.S.;Stein, H.; Banks, P.M.; Chan, J .K.C.; Cleary, M.L.; Delsol, G.; De Wolf-Peeters, C.; Falini, B.; Gatter, K.C.; Grogan, T.M.; I saacson, P.G.; Knowles, D.M.; Mason, D.Y.; Muller-Hermelink, H.K.; Pileri, S.A.; Piris, M.A.; Ralfkiaer, E.; Warnke, R.A. Revised European - American classification of lymphoid neoplasms: a proposal from the International Lymphoma Study Group. Blood 1994; 84: 1.36192.

5- De Gioanni PP, Bosco GF, Modica R. Midline granuloma. A clinical case report. Minerva Stomatol 1993; 42: 107-12.

6- Carbone P, Kaplan HS, Musholf K. Report of the commitee of Hodgkin's diseasestaging classification. Cancer Res 1971; 31: 1.860-1.

7- Cabane J. Qui se cache derrière le granulome malin centrofacial? Ann Méd Interne 1983; 134: 601-5.

8- Lippman SM, Grogan TM, Spier CM, Koopman CF, Gall EP, Shimm DS, Durie BGM. Lethal midline granuloma with a novel $\mathrm{T}$-cell phenocyte as found in peripheral T-cell lymphoma. Cancer 1987; 59: 936-9.

9- Rothacher UM, RumpJ A, Herbst EW, BlumU, Maier W, Peter $\mathrm{HH}$. Differential diagnostic aspects of lethal midline granuIomas. I mmun I nfekt 1994; 22: 158-60.

10- Tsokos M, Fauci A, Costa J . I diopathic midline destructive disease (IMDD). A subgroup of the patients with the "midline granuloma" syndrome. Am J Clin Pathol 1982; 77: 162-8. 